\title{
Capacity Utilisation and Unemployment in Selected West Africa Countries
}

\author{
Alaa M. Soliman \\ Leeds Beckett University, Leeds, England \\ Email: A.Soliman@leedsbeckett.ac.uk
}

How to cite this paper: Soliman, A.M. (2017) Capacity Utilisation and Unemployment in Selected West Africa Countries. Theoretical Economics Letters, 7, 1735-1746.

https://doi.org/10.4236/tel.2017.76117

Received: May 30, 2017

Accepted: October 15, 2017

Published: October 18, 2017

Copyright $\odot 2017$ by author and Scientific Research Publishing Inc. This work is licensed under the Creative Commons Attribution International License (CC BY 4.0).

http://creativecommons.org/licenses/by/4.0/

(c) (i) Open Access

\begin{abstract}
The purpose of this research paper is to examine the proposition that capacity utilisation is an important factor in the determination of unemployment and wages. Underlying this proposition is the notion that capacity utilisation helps to determine the future path of the economy and is a significant factor in the response of the economy to different supply and demand shocks. We derived capacity utilisation and unemployment relationships, which were estimated and tested using data covering from 1997 to 2016 for three West Africa countries. The results suggest that long-term unemployment and capacity utilisation have a significant impact on unemployment. The policy implications of our findings are that in view of the strong effect of capacity utilisation on unemployment, programmes that enhance efficiency in production and investment enhancing policies may allow unemployed to regain access to the labour market.
\end{abstract}

\section{Keywords}

NAIRU, Capacity Utilisation, Unemployment, West Africa

\section{Introduction}

During the period under investigation, from 1997 to 2016, West Africa countries experienced big shocks, which affected their labour and product markets. The dramatic rise in unemployment from 2008 to 2010 in Nigeria and Niger and from 2010 to 2012 in Senegal was attributed by a large extent to adverse demand shocks. However, after the reversal of the shocks, unemployment persisted which economists explained by resorting to notions of inflexibility in the labour markets. Although there appears to be some consensus that changes in labour market institutions and legislation may affect structural unemployment (see, for example, Barrell [1] for the UK), the origins of high and persistent unemploy- 
ment in West Africa region are much debated. This is particularly so, since institutions and legislation were well in place before the high unemployment era. The rise in unemployment during the 1990s, for example, was not associated with any marked increase in labour market "inflexibility".

More recently, attention has been diverted from labour market "flexibility" to the potential impact of changes in interest rates and capital shortage on the unemployment rate that is consistent with non-accelerating inflation (NAIRU), and wages (Allen and Nixon [2], Arestis and Biefang-Frisancho Mariscal [3], Bean [4], Rowthorn [5] [6], Sawyer [7]). Much of the debate on the relationship between capital shortage and unemployment seems to be concerned with the degree of substitutability between labour and capital (Bean [4], Jerger [8], Rowthorn [6]). In response to the fluctuations in oil prices, contractionary monetary and fiscal policies were introduced which squeezed profits and investment, so that capital stock fell below a level adequate for high levels of employment. Real wages were too high for changed productivity conditions and excessive substitution of capital for labour with a prevalence of capital intensive investment was introduced. As a result, labour requirement for any given level of output was reduced. As a consequence of the pace and quality of capital accumulation, the level of employment corresponding to full utilisation of capital stock was lower than that would correspond with full employment (however that may be measured). Gordon [9] finds that countries that experienced the largest slowdown in capital accumulation per labour hour faced the highest unemployment rates. He concluded that the European countries did not have sufficient capital in the 1980s to equip all employees who would have had a job if unemployment rates remained the same as in the 1970s. Bean [4] predicted a similar result. Capacity utilisation adjustment is an important mechanism ensuring adjustment to the macroeconomic equilibrium. Low capacity utilisation is a concern for fiscal and monetary authorities that are willing to engage in simulation aiming particularly at the level of unemployment. The argument of this study is that low capacity utilisation leads to higher unemployment which in turn creates even greater slake in the economy. The main research question which remains unanswered in the literature, is how the labour market reacts to capacity utilisation changes.

The aim of this paper is to examine the proposition that capacity utilisation is a determinant of the rate of unemployment and the level of real wages in a range of West Africa countries. The following three West Africa countries were selected on the basis of purely data availability and consistency: Nigeria, Niger and Senegal. We argue that adverse demand shocks affect investment. When shocks reverse, unemployment may not fall to previous levels, due to the fact that recovery of employment takes longer than the recovery of output. One of the reasons could be that firms do not want to make a commitment to hiring new workers until there is a certain level of certainty about the strength and sustainability of the recovery.

The layout of the paper is the following: Section 1 highlights the literature on 
capital stock and unemployment; Section 2 outlines the theoretical modelling approach; Section 3 describes the data and presents the empirical findings; Section 4 summarises the main findings and offers some concluding remarks.

\section{A Theoretical Model of Unemployment Determination}

In this part we put forward a model that aims to explain the determination of wages and unemployment. Specific to this model is the effect of capacity utilisation on unemployment.

Unlike some studies that postulate that the long-run impact of capital accumulation on the rate of unemployment occurs through the impact of the former on firms' mark-ups, we postulate a different framework in which unemployment is determined by capacity utilisation in the economy.

The short-run profit maximising decision facing the typical firm, $i$, consists of maximising profits

$$
\max p f\left(y_{t}^{i}\right)-w_{i}^{e} l
$$

where $(p y)$ is the maximum profit minus cost of labour $w_{i}^{e} l$. Firms in Equation (1) are constrained by the production function. Equation (1) is a simple maximisation problem of one variable, so we take the first derivative of the function and set it equal to zero, we get:

$$
p f\left(y_{t}^{i}\right)-w_{i}^{e} l=0
$$

where, we denote by $f\left(y_{t}^{i}\right)$ the derivative of the production function with respect to $y_{t}^{i}$. It is simply the slope of the production function at $y_{t}^{i}$ or the marginal product of $y_{t}^{i}$. Thus Equation (2) is saying that at optimum we must have:

$$
p m p_{t}^{l}=w_{t}^{e}
$$

Assuming that the economy consists of a number, $n$, of identical firms, using an equal amount of capital and labour with the same level of technology, then at optimum with, $f$, mark-up, we must have:

$$
p y_{t}=f_{t} \cdot \frac{w_{t}^{e}}{m p_{t}^{l}}
$$

where $m p_{t}^{l}$ is the marginal product of labour and $f_{t}$ is a mark-up set by firms in the economy.

Computing the optimal choice at $y_{t}^{i}$ for Cobb-Douglas production function, the economy's output is equal to:

$$
y_{t}=\gamma_{0} \cdot \lambda^{t} \cdot L_{t}^{\alpha} \cdot K_{t}^{1-\alpha}
$$

where $L$, is employment, $K$ is the amount of capital, $\gamma_{0}$ is constant and $\lambda^{t}$ is the rate of technological change.

Differentiating Equation (5) with respect to capital we can obtain the marginal product of capital as:

$$
\xi_{t}^{k}=\gamma_{0} \cdot \lambda^{t}(1-\alpha) \cdot\left(K_{t}\right)\left(L_{t}\right)^{-\alpha} \succ 0
$$


Also differentiating Equation (5) with respect to employment, we get the marginal product of labour or:

$$
\xi_{t}^{l}=\gamma_{0} \cdot \lambda^{t} \alpha\left(K_{t}\right)\left(L_{t}\right)^{1-\alpha} \succ 0
$$

In order to minimise capital and labour costs, a typical firm will have:

$$
\frac{\partial K}{\partial L}=\frac{-\lambda_{t}^{l}}{\lambda_{t}^{k}}=\frac{-w / p}{r}
$$

Combining Equations (6)-(8), the marginal product of labour is:

$$
\xi_{t}^{l}=\gamma_{0}^{1 / \alpha} \cdot \lambda^{\alpha} \cdot \alpha \cdot(K / L)^{\frac{1-\alpha}{\alpha}}
$$

Assuming that the level of economic activity, captured by the level of unemployment, is influenced by the cyclicality of mark-ups, $m_{t}$, and aggregate capacity utilisation, $z_{t}$, which can be represented by the following equation:

$$
U_{t}=m_{t} \cdot z_{t}^{\tau}
$$

where $t$, captured the level of uncertainty in the economy. If $z_{t} \succ 0$, then the increase in capacity utilisation will raise the NAIRU and vice-versa.

Taking the logarithms of Equation (10), we get:

$$
\ln U_{t}=\ln m_{t}+\tau \cdot z_{t} \quad \text { where } z_{t}=\ln z_{t}
$$

Also taking the logarithms in Equation (4) yields:

$$
\ln z_{t}-\ln w_{t}^{e}=\ln m_{t}+m z_{t}
$$

Inserting Equation (12) into Equation (11) yields

$$
\ln z_{t}-\ln w_{t}^{e}=\ln m_{t}+t z_{t}
$$

Re-writing Equation (10)

$$
\ln U_{t}=\ln z_{t}-\ln w_{t}^{e}
$$

Both Equation ((13) and (14)) can be used to solve for the equilibrium rate of unemployment, where unemployment is a declining function of capacity utilisation. The effect of changes in capacity utilisation on unemployment can be explained as follow. If capacity utilisation is reduced or taxes or import costs rise, conflict over income distribution rises. Taking as an example the fall in oil prices in the early 1980s, which led to a fall in demand and then a reduction in capacity utilisation. Firms respond by reducing investment, which led to a lower (than otherwise) capital stock, which increases the NAIRU. In order to bring inflation down, governments introduced monetary and fiscal policies that reduce the supply-demand imbalance caused by the fall in capacity utilisation in response to fall in overall investment. As a result, unemployment rose. When oil prices return to their previous level, inflationary pressure and unemployment fall. However, due to a lower capital stock, the previous level of employment cannot be attained.

Estimable Equations

We proceed to formulate the equations to be estimated, by assuming that ex- 
pectations are formed as in Nickell [10], that is:

$$
s_{t+1}^{e}=s_{t}+\Delta s_{t}
$$

where $\Delta s_{t}=s_{t}-s_{t-1}$

We also assume that Equations ((13) and (14)) describe a log-linear relationship. After some basic algebraic transformations, we may derive Equation (16):

$$
\begin{aligned}
\Delta U_{t}= & \alpha_{1} p l_{t}+\alpha_{2} \Delta p l_{t}+\alpha_{3}(w-p)_{t}+\alpha_{4} \Delta(w-p)_{t} \\
& +\alpha_{5}(z)_{t}+\alpha_{6} \Delta(z)_{t}+\alpha_{7} i t_{t}+\alpha_{7} \Delta i t_{t}+v
\end{aligned}
$$

1where lower case letters denote the logarithm of a variable.

Equation (16) can be described as follows: Unemployment $(\Delta U)$ depends on real wages $(w-p)$, labour productivity $(p I)$, capacity utilisation level $(z)$, tax and import costs (it). The long-run unemployment equation can be obtained by setting $\Delta(w-p), \Delta(z), \Delta p l, \Delta i t$, equal to zero and we further assume that the NAIRU relationship is linear in logs so that we may write:

$$
u=\beta_{0}+\beta_{1}(w-p)+\beta_{2}(z)+\beta_{3} i t
$$

\section{Empirical Investigation}

The first part of the empirical section discusses the data utilised for the three countries concerned. This is followed by the estimation of cointegrating relationships corresponding to Equations ((14) and (15)). We apply the standard Johansen [11] maximum likelihood estimation procedure to estimate the number of linearly independent cointegrating vectors. Identifying restrictions on the cointegrating vectors are then imposed and tested for lying in the cointegrating space spanned by the cointegrating vectors.

\section{Variable definition and data}

The selected countries are Nigeria, Niger and Senegal, which exhibit consistency in the data. The model is estimated using quarterly data for the period $1997 q 1$ to $2015 q 4$ for Niger and Senegal. For Nigeria, the estimation period is up to 2016q2. The definition of variables for all countries are as follows: the long-term unemployed (LU) are those unemployed who are so for more than 52 weeks in relation to the labour force; $(t i)$ accounts for claims by foreign and government sectors and defined as the gap between consumer and product wage, computed as: $t i=T x_{2}+T x_{1}+\left(p_{c}-p_{y}\right)$, where $T x_{2}$ is the tax rate paid by employers, $T x_{1}$ is the tax rate on employee earnings, $p_{c}$ is consumer price deflator and $p_{y}$ is GDP price deflator; capacity utilisation $(k)$ measures the proportion of potential economic output that is actually realised; $(u)$ is the unemployment rate, computed as total unemployment divided by total labour force.

\section{Empirical results}

All variables were tested for the level of integration, applying the standard Augmented Dickey-Fuller (ADF) unit root tests with the result that all variables have unit roots. ${ }^{1}$ In a preliminary analysis we estimated and tested an unre-

${ }^{1}$ The results of these tests can be obtained from the authors on request. 
stricted vector autoregressive (UVAR) model, including a constant, deterministic trend and various dummy variables, where the latter capture outliers. The wage equation for Nigeria has one impulse dummy which captures government intervention following the devaluation of the Nira in June 2016 and an impulse dummy with the value one for 2003Q1 was included in the unemployment equation to capture the fluctuations in oil process due to the second Gulf War. The Akaike (AIC) and Schwarz Bayesian (SBC) information criteria were applied in order to determine the optimal lag lengths of the VAR. The two criteria are designed to select the model with the optimal empirical lag length ${ }^{2}$.

We started with a maximal lag length of five for all countries. The optimal empirical lag length can be found in Table 2 of Appendix. In cases where the results of the information criteria were contradictory, we decided on the longer lag length provided by the Akaike information criterion to avoid misspecification, particularly serial correlation Stock [12] as reported in Table 1. The UVAR was tested for misspecification and we found that for all countries, except for Senegal, where we were not able to capture violations of normality in all equations, the test results were satisfactory. The violation of the normality assumption may affect the cointegration tests. There is evidence, that the trace test is in this case the preferred statistic. As we will see below, both tests suggest two cointegrating vectors for Senegal.

The results of Johansen's [11] [13] likelihood-based cointegration tests are reported in Table 2. The cointegrating VAR was estimated with unrestricted intercepts and restricted trends. The deterministic trends were included because the data are trended and omitting them would have caused mis-specified models. The null hypothesis of the cointegration tests is that there is no cointegrating vector and the alternative is that there is at most one cointegrating vector. Table 3 shows that the non-cointegration hypothesis is rejected at the $5 \%$ level of significance in all three countries, also that there are at least two cointegrating vectors in each of all three countries. The two cointegrating vectors are reported in the sub-section that follows immediately below.

\section{Cointegrating vector for real wages and unemployment}

The two cointegrating vectors as discussed in the last sub-section, may not be

Table 1. Selection of the order of the VAR.

\begin{tabular}{ccccccccccc}
\hline & \multicolumn{1}{c}{ AIC } & \multicolumn{7}{c}{ SIC } \\
\hline & 1 & 2 & 3 & 4 & 5 & 1 & 2 & 3 & 4 & 5 \\
\hline Nigeria $\left(5^{\star}\right)$ & 63.4 & 68.7 & 69.2 & 81.6 & 82.7 & 59.5 & 61.5 & 57.3 & 67.7 & 64.6 \\
Niger $\left(4^{\star}\right)$ & 65.6 & 76.6 & 79.7 & 56.5 & 69.6 & 61.2 & 69.4 & 68.7 & 42.7 & 52.1 \\
Senegal $\left(5^{*}\right)$ & 31 & 38.6 & 38.1 & 37.2 & 39.5 & 23.1 & 24.5 & 18.2 & 10.8 & 6.5
\end{tabular}

AIC and SIC stand for Akaike information and Schwartz information criteria respectively. An asterisk $\left.{ }^{*}\right)$ indicates the selected lag length.

${ }^{2}$ To select the optimal lag length of the VAR, these criteria for model choice are necessary but not sufficient. 
Table 2. Johansen cointegration tests trace statistic results.

\begin{tabular}{cccccccc}
\hline & \multicolumn{7}{c}{$\mathrm{H}_{0}$ :r $=$ Summary } \\
\hline & 0 & 1 & 2 & 3 & 4 & 5 & $\mathrm{r}^{\mathrm{a}}$ \\
\hline Nigeria & 147.1 & 89.7 & 44.7 & 25.1 & 12.7 & 4.0 & 2 \\
Niger & 133.4 & 89.9 & 77.4 & 65.8 & 12.7 & $(\mathrm{NA})$ & 3 \\
Senegal & 173.5 & 101.8 & 59.6 & 34.3 & 17.9 & 6.8 & 2 \\
\hline
\end{tabular}

a Number of cointegrating vectors identified using the trace statistic, $1 \%$ significance level.

Table 3. Vector Error Correction Models.

\begin{tabular}{|c|c|c|c|}
\hline & Nigeria & Niger & Senegal \\
\hline & $\Delta \mathrm{u}$ & $\Delta \mathrm{u}$ & $\Delta \mathrm{u}$ \\
\hline \multirow[t]{2}{*}{ Cointegrating Vectors } & -0.032 & -0.0142 & 0.172 \\
\hline & $(0.251)$ & $(1.325)$ & $(2.861)$ \\
\hline \multirow[t]{2}{*}{$\Delta \mathrm{w}-\mathrm{p} \cdot \mathrm{lp}_{-1}$} & -0.062 & -0.532 & -0.042 \\
\hline & $(-0.761)$ & $(-2.342)$ & $(-0.021)$ \\
\hline \multirow[t]{2}{*}{$\Delta \mathrm{u}_{-1}$} & -0.0541 & -0.531 & -0.006 \\
\hline & $(0.066)$ & $(0.181)$ & $(-0.612)$ \\
\hline \multirow[t]{2}{*}{$\Delta \mathrm{LU}_{-1}$} & -0.201 & -0.332 & -0.421 \\
\hline & $(-0.001)$ & $(-0.012)$ & $(-0.015)$ \\
\hline \multirow[t]{2}{*}{$\Delta \mathrm{k}_{-1}$} & -0.262 & -0.271 & -0.841 \\
\hline & $(-1.031)$ & $(-0.514)$ & $(-0.006)$ \\
\hline \multirow[t]{2}{*}{$\Delta \mathrm{ti}_{-1}$} & -0.006 & 1.542 & -0.018 \\
\hline & $(-0.071)$ & $(-0.931)$ & $(-0.002)$ \\
\hline $\mathrm{R}^{2}$ & 0.721 & 0.492 & 0.791 \\
\hline F-statistic & 2.542 & 2.901 & 2.103 \\
\hline Log likelihood & 192.092 & 174.936 & 241.952 \\
\hline Akaike AIC & -3.932 & -4.921 & -3.923 \\
\hline Schwarz SC & -3.361 & -5.172 & -3.021 \\
\hline
\end{tabular}

meaningful in an economic sense. They span a space in which any linear combination is another cointegrating relationship. Since the Johansen's reduced rank regression procedure only determines how many unique cointegration vectors span the cointegration space, and since any linear combination of the stationary vectors is also a stationary vector, the estimates produced for any particular column in $\beta$ are not necessarily unique. Therefore, it will be necessary to impose restrictions to obtain unique vectors lying within that space Harris [14]. Consequently, general joint restrictions on the cointegration vectors, $\beta$, and the speedof-adjustment parameters, $\alpha$, according to the theoretical model were imposed and tested for significance Harris [14], Hendry Doornik and Hendry [15] 
Hunter [16], and Mosconi and Giannini $[17]^{3}$. A $\chi^{2}(n)$ test is used as shown below the $\alpha$ estimates in the sub-section "Cointegrating vector for real wages and unemployment". The likelihood ratio test accepts the joint restrictions for the three countries. ${ }^{4}$ The speed-of-adjustment parameters for all equations are also reported. The adjustment parameters reported here indicate the time period it takes to adjust wage and unemployment growth with respect to a disequilibrium error in the two identified cointegrating vectors. For all three countries, the adjustment parameters are significant and correctly signed.

The cointegrating vectors for the three countries (the variables are as above, with the exception of $\mathrm{Tr}$ which stands for deterministic trend) are now reported below:

Nigeria

$$
u=0.66 \mathrm{LU}+0.40 t i-0.05 k+0.00(w-p c-l p)+0.002 \mathrm{Tr}
$$

$$
(\mathrm{NA})(0.20) \quad(0.12) \quad(\mathrm{NA}) \quad(\mathrm{NA}) \quad(0.00)
$$

$\alpha$

$$
\begin{array}{lrr}
u & -0.053 & -0.0820 \\
\chi^{2}(5)=4.2511 & (0.1462)
\end{array}
$$

Niger

$$
\begin{aligned}
& u=0.36 \mathrm{LU}+0.00 t i-0.21 k+0.00(w-p c-l p)+0.04 \mathrm{Tr} \\
& (\mathrm{NA})(0.08) \quad(\mathrm{NA})(0.11) \quad(\mathrm{NA})
\end{aligned}
$$

$\alpha$

$$
\begin{array}{lrr}
u & 0.2410 & -0.0594 \\
\chi^{2}(5)=5.7951 & (0.1220)
\end{array}
$$

\section{Senegal}

$$
\begin{aligned}
& u=0.54 \mathrm{LU}+0.00 t i-0.39 z+0.00(w-p c-l p)+0.04 \mathrm{Tr} \\
& (\mathrm{NA})(0.08) \quad(\mathrm{NA})(0.11) \quad(\mathrm{NA})
\end{aligned}
$$

$\alpha$

$$
\begin{aligned}
& u \quad-0.0985-0.0826 \\
& \chi^{2}(5)=4.251 \quad(0.112)
\end{aligned}
$$

The values in brackets are the estimated probability levels. (NA) denotes that the coefficient was restricted in the identifying procedure. The first equation for each country describes the average hourly wage per unit of output ( $w$ - $p-l p)$, determined by the logarithm of unemployment $(u)$, long term unemployment (LU), capacity utilisation ( $k$ ), capital accumulation (i), the tax-and import costs $(t i)$, and a deterministic trend ( $\mathrm{Tr})$. The second equation explains unemployment by long-term unemployment, capacity utilisation, and a deterministic ${ }^{3}$ General restrictions on $\alpha$ and $\beta$ may be expressed directly as a function of the unrestricted elements of $\alpha$ and $\beta$.

${ }^{4}$ Deriving the degrees of freedom involved in the $\mathrm{chi}^{2}$ test is not straightforward, especially when $a$ restrictions are involved. The number of degrees of freedom in our empirical results does not reflect the number of restrictions imposed. 
trend. All variables are correctly signed and significant. The adjustment coefficient $(\alpha)$ for the dynamic wage and unemployment equations, has the expected negative sign in all cases. The $\chi^{2}(n)$ statistic is insignificant in all instances. The identifying restrictions for the wage equation are 1 for $(w-p-l p)$ and 0 for the capacity utilisation variable $z$ (except for Senegal) and the tax- and import costs variable $t i$. The unemployment equation has three restrictions imposed (with the exception of two restrictions imposed for Nigeria, two just-identifying and one-overidentifying restrictions. The restrictions are on the following coefficients: $(w-p-l p)=0, u=-1$, and $t i=0$. The likelihood ratio test accepts the overidentifying restriction for all three countries.

To assess the impact of cross-country differences, panel estimations were carried out to clarify whether or not the Economic Community of West Africa States (ECOWAS) can be treated as one homogeneous whole. Fixed effects balanced panel estimations were carried out using a time-demeaning procedure suggested by Wooldridge (2002) for the three countries under study, over the period 1997Q1-2015Q4, the time period for which data were available for all the three countries. The results from the estimation of the VEC model from the fixed effects panel estimation are reported in Table 4.

For Nigeria, tax and import costs are significant in the unemployment equation. Tax costs raise the NAIRU significantly. Long-term unemployment has a significant effect on raising both real wages and the NAIRU. These results suggest that the effect of higher long-term unemployment (relative to total unemployment) is to raise real wages, rather than the usually supposed mechanism of

Table 4. Panel vector error correction results.

\begin{tabular}{cc}
\hline Error correction & $\Delta \mathrm{u}$ \\
\hline Cointegrating Vectors & -0.027 \\
$\Delta$ w-p.lp ${ }_{-1}$ & $(-2.251)$ \\
& -0.719 \\
$\Delta \mathrm{u}_{-1}$ & $(-0.461)$ \\
& 0.954 \\
$\Delta \mathrm{LU}_{-1}$ & $(-0.851)$ \\
& -0.514 \\
$\Delta \mathrm{k}_{-1}$ & $(-0.328)$ \\
& -0.012 \\
$\Delta \mathrm{ti}_{-1}$ & $(-0.549)$ \\
& -1.015 \\
$\mathrm{R}^{2}$ & $(-0.001)$ \\
F-statistic & 0.522 \\
Akaike AIC & 11.821 \\
Schwarz SC & -2.523 \\
& -2.318 \\
\hline
\end{tabular}

$\mathrm{t}$ ratios in square brackets. 
excess supply of labour reducing real wages. Investment in productive capacity reduces the NAIRU significantly. Both $\alpha$ 's for the first cointegrating vector and the second cointegrating vector are significant, and show the right sign (negative).

For Nigeria, the unemployment equation is particularly interesting in that there is a significant impact on unemployment in response to changes in capacity utilisation. Long-term unemployment also has a significant effect on both, real wages and the NAIRU. For Niger, there is significant impact on (the equilibrium level of) unemployment in response to changes in capacity utilisation. We also find that there is a significant impact on real wages in response to changes in capacity utilisation. For both countries, the real wage and the unemployment equation, tax and import costs were insignificant. We obtain similar results for Senegal, however, long-term unemployment has a significant effect on both, real wages and the NAIRU. The cointegrating VAR included a proxy meant to capture unemployment benefits which, however, proved to be insignificant, and was consequently dropped. As for Nigeria and Senegal, tax and import costs were not found to have any effect on both real wages and unemployment equations. Note, for all three countries, long-term unemployment increases wages, a result, which confirms the insider-outsider theory. The long-term unemployed are effectively excluded from the labour force so that a rise in the pool of the long-term unemployed (relative to total unemployment) strengthens insiders' bargaining power and raises wages. Consequently, a relative rise in long-term unemployment allows insiders (those who are employed of only recently unemployed) to press for higher wages, regardless of the general increase in the unemployment rate.

\section{Summary and Conclusions}

We have presented an innovative aggregate unemployment model, which incorporates a number of ideas on unemployment and wage determination, and the model is concerned with explaining the long-run level of unemployment. In this model, the effect of demand on unemployment and wages is emphasised. The mechanism works through changes in capacity utilisation, which themselves depend on economic activity and the stock of capital. We derived capacity utilisation and unemployment relationships, which were estimated and tested with comparable data sets for all three countries. For all the three countries the data sets provided two cointegrating vectors, which could be identified as unemployment and capacity utilisation relationships. The empirical results, based on quarterly time series data for three countries, can be summarised as follows.

The results show that in Senegal, long-term unemployment and capacity utilisation have a significant impact on NAIRU, while tax and import costs significantly raise unemployment in Nigeria. However, the results show that there is little evidence that in the long run, a tax cut reduces unemployment or real wages. For Niger, there is significant impact on (the equilibrium level of) unem- 
ployment in response to changes in capacity utilisation. We also find that there is a significant impact on real wages in response to changes in capacity utilisation. For both Nigeria and Niger, the real wage and the unemployment equation, tax and import costs were insignificant.

The policy implications of our findings are that in view of the strong effect of long-term unemployment on the NAIRU, programmes that enhance the skills of displaced workers may allow them to regain access to the labour market. Furthermore, the results suggest that capacity utilisation significantly affects unemployment. This is important since investment-enhancing policies can lead the way in reducing unemployment.

\section{References}

[1] Barrell, R. (1994) The UK Labour Market. Cambridge University Press, Cambridge.

[2] Allen, C. and Nixon, J. (1997) Two Concepts of the NAIRU. In: Allen, C. and Hall, S., Eds., Macroeconomic Modelling in a Changing World, Wily, New York.

[3] Arestis, P. and Biefang-Frisancho Mariscal, I. (2000) Capital Shortages, Unemployment and Wages in the UK and Germany. Scottish Journal of Political Economy, 47, 487-503. https://doi.org/10.1111/1467-9485.00175

[4] Bean, C.R. (1989) Capital Shortage and Persistent Unemployment. Economic Policy, 4, 12-53. https://doi.org/10.2307/1344463

[5] Rowthorn, R.E. (1995) Capital Formation and Unemployment. Oxford Review of Economic Policy, 11, 26-39. https://doi.org/10.1093/oxrep/11.1.26

[6] Rowthorn, R.E. (1999) Unemployment, Wage Bargaining and Capital-Labour Substitution. Cambridge Journal of Economics, 23, 413-426. https://doi.org/10.1093/cje/23.4.413

[7] Sawyer, M. (2002) The NAIRU, Aggregate Demand and Investment. Metroeconomica, 53, 66-94. https://doi.org/10.1111/1467-999X.00137

[8] Jerger, J. (1991) Wage Gaps, Capital Formation and Unemployment. Jahrbuecher fuer Nationaloekonomie und Statisik, 208, 264-271.

[9] Gordon, R. (1997) Is There a Trade-Off Between Unemployment and Productivity Growth? In Snower, D.J. and De la Dehesa, G., Eds., Unemployment Policy: Government Options for the Labour Market, Cambridge University Press, Cambridge. https://doi.org/10.1017/CBO9780511752025.033

[10] Nickell, S. (1990) Unemployment: A Survey. Economic Journal, 106, 391-439. https://doi.org/10.2307/2234131

[11] Johansen, S. (1988) Statistical Analysis of Cointegrating Vectors. Journal of Economic Dynamics and Control, 12, 231-254.

https://doi.org/10.1016/0165-1889(88)90041-3

[12] Stock, J.M. (1994) Unit Roots, Structural Break and Trends. In: Engle, R.F. and McFadden, D., Eds., Handbook of Econometrics, North Holland, 2738-2841.

[13] Johansen, S. and Juselius, K. (1992) Testing Structural Hypotheses in a Multivariate Cointegration Analysis of the PPP and the UIP for UK. Journal of Econometrics, 53, 211-244. https://doi.org/10.1016/0304-4076(92)90086-7

[14] Harris, R.I.D. (1995) Using Cointegration Analysis in Econometric Modelling. Prentice Hall, London.

[15] Doornik Jurgen, A. and David, F.H. (1997) Modelling Dynamic Systems Using 
PcFiml 9.0. International Thomson Business Press, New Jersey.

[16] Hunter, J. (1992) Cointegrating Exogeneity. Economics Letters, 34, 33-35. https://doi.org/10.1016/0165-1765(90)90177-3

[17] Mosconi, R. and Giannini, C. (1992) Non-Causality in Cointegrated System: Representation, Estimation and Testing. Oxford Bulletin of Economics and Statistics, 48, 300-417. 